\title{
Silylation of Alcohols and Phenols with Hexamethyldisilazane over Highly Reusable Propyl Sulfonic Acid Functionalized Nanostructured SBA-15
}

\author{
Daryoush ZAREYEE*, Rezvaneh ASGHARI, Mohammad A. KHALILZADEH \\ Department of Chemistry, Qaemshahr Branch, Islamic Azad University, Qaemshahr, Iran
}

\begin{abstract}
Various alcohols and phenols were trimethylsilylated in excellent yields using hexamethyldisilazane in the presence of catalytic amounts of environmentally friendly, hydrophobic, highly thermal stable, and completely heterogeneous sulfonic acid functionalized mesostructured SBA-15 in dichloromethane at ambient temperature. Primary, bulky secondary, tertiary, and phenolic hydroxyl functional groups were transformed to the corresponding trimethylsilyl ethers in excellent yields. The simple experimental procedure was accompanied by easy recovery and the catalyst was reusable (at least 18 reaction cycles); these are attractive features of this protocol.
\end{abstract}

Key words: reusable heterogeneous catalyst; solid sulfonic acid; SBA-15; protecting group; silylation; hexamethyldisilazane

CLC number: $0643 \quad$ Document code: A

Received 6 July 2011. Accepted 3 November 2011.

*Corresponding author. Tel:+98-123-214-5048; Fax: +98-123-214-5050; E-mail: zareyee@gmail.com, zareyee.d@qaemshahriau.ac.ir English edition available online at Elsevier ScienceDirect (http://www.sciencedirect.com/science/journal/18722067).

The protection of the hydroxyl function in alcohols and phenols is a common and versatile part of many syntheses of reasonable complexity. Among the routinely employed methodologies for the masking of hydroxyl groups in organic chemistry, the transformation of alcohols to the corresponding silyl ethers is a popular procedure [1,2]. The popularity and extensive use of silyl ethers as protecting groups for alcohols come from their ease of formation, resistance to oxidation, good stability toward most non-acidic reagents, and easy deprotection to provide free alcohols [3]. Although many reagents are available for the silylation of hydroxyl groups [4-13], some of these methods suffered from serious drawbacks such as the lack of reactivity, low product yields, long reaction times, expensive reagents and catalysts, and robust purification steps or difficulty in by-product removal. In contrast, 1,1,1,3,3,3-hexamethyldisilazane (HMDS) is a cheap, easy handling, commercially available and stable reagent, and it is frequently used for the trimethylsilylation of hydroxyl groups giving ammonia as the only by-product. However, the main drawback of HMDS is its poor silylating power as it needs forceful conditions and long reaction times in many instances [14]. Therefore, a variety of catalysts have been developed for the activation of this reagent such as sulfuric acid [2], $\left(\mathrm{CH}_{3}\right)_{3} \mathrm{SiCl}$ [15], sulfonic acids [16], K-10 montmorillonite $[17,18]$, iodine [19], tungstophosphoric acid $\left(\mathrm{H}_{3} \mathrm{PW}_{12} \mathrm{O}_{40}\right)$ [20], $\mathrm{LiClO}_{4}$ [21], TBBDA and PBBS [22], $\left[\mathrm{PdCl}\left(\eta^{3}-\mathrm{C}_{3} \mathrm{H}_{5}\right)\right]_{2}-\mathrm{PPh}_{3}$ [23], $\mathrm{HReO}_{4}$ [24], $\mathrm{LaCl}_{3}$ [25], tri- bromomelamine [26], $\mathrm{Bi}(\mathrm{OTf})_{3}$ [27], tribromoisocyanuric acid and DABCO-Br [28]. Although the silylation ability of HMDS has been improved by these methods some problems such as the use of a corrosive catalyst, drastic reaction conditions, tedious workup, and long reaction times still need to be overcome. Moreover, many of these reagents are expensive and non-recoverable leading to the generation of a large amount of toxic waste particularly when large-scale applications are considered. In other words, the tightening of legislation with regard to the treatment and disposal of toxic waste produced during the difficult separation of the desired products is forcing industry to consider greener technologies. Therefore, solid acids catalysis is a growing field of research as the demand for clean and eco-friendly chemical processes is increasing [29-34]. Accordingly, chemical industry is currently searching for highly active, stable, and recyclable solid acids to improve the environmental safety of the production of chemicals under milder reaction conditions. To address these issues, Zareyee and Karimi [35] demonstrated the application of recoverable sulfonic acid functionalized ordered mesoporous silica (MCM-41Pr- $\mathrm{SO}_{3} \mathrm{H}$ ) for the efficient silylation of alcohols and phenols. Quite recently, they used a heterogeneous and hydrophobic sulfonic acid nanoreactor with acidic sites and phenyl groups within the mesochannel of SBA-15 as an efficient, environmentally benign, and highly recoverable catalyst for the Pechmann [36] and Strecker [37] reactions. In the course of our ongoing green organic chemistry program and 
current interest in the development of nanostructured solid acids for different organic transformations [35-39], we report on a brief preparation and application of a sulfonic acid nanoreactor (SBA-15-Ph-Pr- $\left.\mathrm{SO}_{3} \mathrm{H}\right)$ for the trimethylsilylation of hydroxyl groups.

\section{Experimental}

\subsection{Preparation of SBA-15-Ph-Pr-SO $\mathrm{S}_{3} \mathrm{H}$}

The synthesis of SBA-15-Pr-SH was achieved using the known procedure described by Stucky et al. [40]. This procedure involved a synthetic strategy based on the co-condensation of tetraethoxysilane (TEOS) and 3-mercaptopropyltrimethoxysilane (MPTMS) in the presence of Pluronic P123 as the structure directing agent. In a typical preparation procedure, $4 \mathrm{~g}$ of Pluronic P123 (Aldrich, average $M_{\mathrm{w}}=5800$ ) was dissolved in $125 \mathrm{~g}$ of 1.9 $\mathrm{mol} / \mathrm{L} \mathrm{HCl}$ solution with stirring at room temperature. The solution was heated to $40{ }^{\circ} \mathrm{C}$ before adding $6.83 \mathrm{~g}$ TEOS. After a $3 \mathrm{~h}$ pre-hydrolysis of TEOS, $1.6 \mathrm{~g}$ thiol precursor MPTMS was added. The resultant solution was stirred for $20 \mathrm{~h}$ at $40{ }^{\circ} \mathrm{C}$ after which the mixture was aged at $100{ }^{\circ} \mathrm{C}$ for $24 \mathrm{~h}$ under static conditions. The solid was recovered by filtration and air dried at room temperature overnight. The template was removed from the as-synthesized material by washing with ethanol using a Soxhlet apparatus for $24 \mathrm{~h}$.

To a suspension of SBA-15-Pr-SH (3 g) in dry toluene $\mathrm{PhSi}(\mathrm{OEt})_{3}$ (PTES, 4 mmol) was added. The resulting mixture was first stirred at room temperature for $1 \mathrm{~h}$ and then refluxed for a further $24 \mathrm{~h}$. The solid material was filtered and successively washed with toluene, $\mathrm{EtOH}$, and $\mathrm{Et}_{2} \mathrm{O}$ and dried overnight at $120{ }^{\circ} \mathrm{C}$ to afford the corresponding SBA-15-Ph-Pr-SH.

Conversion of the catalyst's thiol groups to sulfonic acid moieties was accomplished by hydrogen peroxide. Typically, $0.3 \mathrm{~g}$ of solid hydrophobic material was suspended in $10 \mathrm{~g}$ of aqueous $30 \mathrm{wt} \% \mathrm{H}_{2} \mathrm{O}_{2}$. This suspension was stirred at room temperature in an Ar atmosphere for $24 \mathrm{~h}$. After the oxidation treatment, the resulting solution was filtered and washed separately with water and ethanol. Finally the wet material was suspended in $1 \mathrm{~mol} / \mathrm{L} \mathrm{H}_{2} \mathrm{SO}_{4}$ solution for $2 \mathrm{~h}$ and it was then washed several times with water and ethanol and dried at $60{ }^{\circ} \mathrm{C}$ under vacuum overnight to give the corresponding SBA-15-Ph-Pr-SO $\mathrm{S}_{3} \mathrm{H}$, denoted as catalyst $\mathbf{1}$ (Fig. 1).

The concentration of sulfonic acid groups in catalyst $\mathbf{1}$ was quantitatively estimated by ion-exchange $\mathrm{pH}$ analysis. To an aqueous solution of $\mathrm{NaCl}(1 \mathrm{~mol} / \mathrm{L}, 25 \mathrm{ml})$ with a primary $\mathrm{pH}$ of 5.1 the catalyst $1(100 \mathrm{mg})$ was added and the resulting mixture was stirred for $6 \mathrm{~h}$ after which the $\mathrm{pH}$ of the solution decreased to 2.19 .

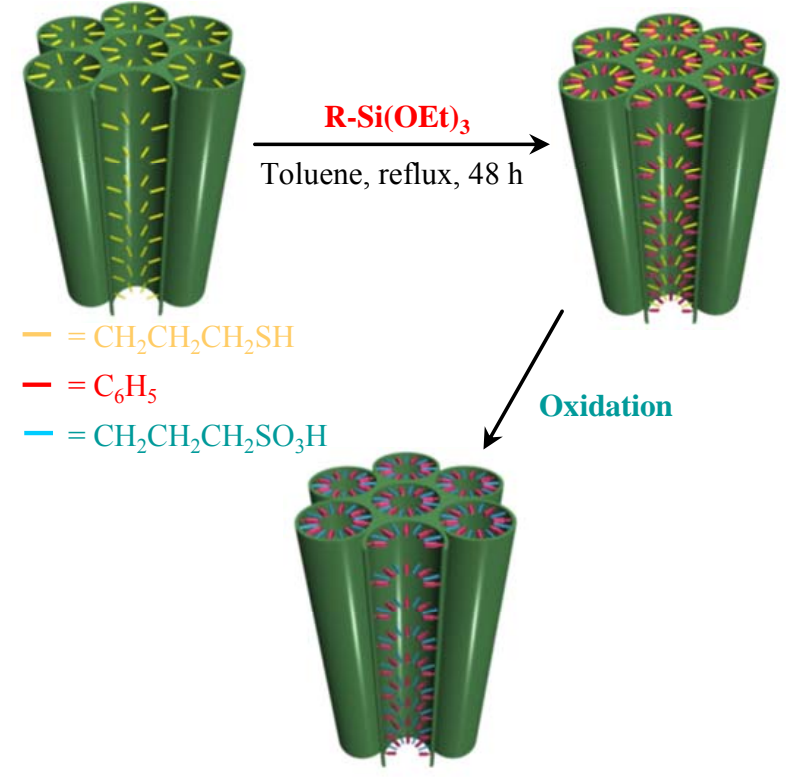

Fig. 1. Schematic representation of the preparation of the sulfonic acid based catalyst $\mathbf{1}$.

\subsection{General procedure for the trimethylsilylation of alcohols}

To a solution of alcohol ( $1 \mathrm{mmol})$ and HMDS $(0.6 \mathrm{mmol})$ in dichloromethane $(3 \mathrm{ml})$ catalyst $1(19 \mathrm{mg}, 3 \mathrm{~mol} \%)$ was added. The mixture was stirred at $35^{\circ} \mathrm{C}$ for a period of time (Fig. 2). Reaction progress was monitored by thin layer chromatography (TLC) and gas chromatography (GC). After the completion of the reaction the product was isolated by filtration. Evaporation of the solvent under reduced pressure gave the corresponding silyl ether.

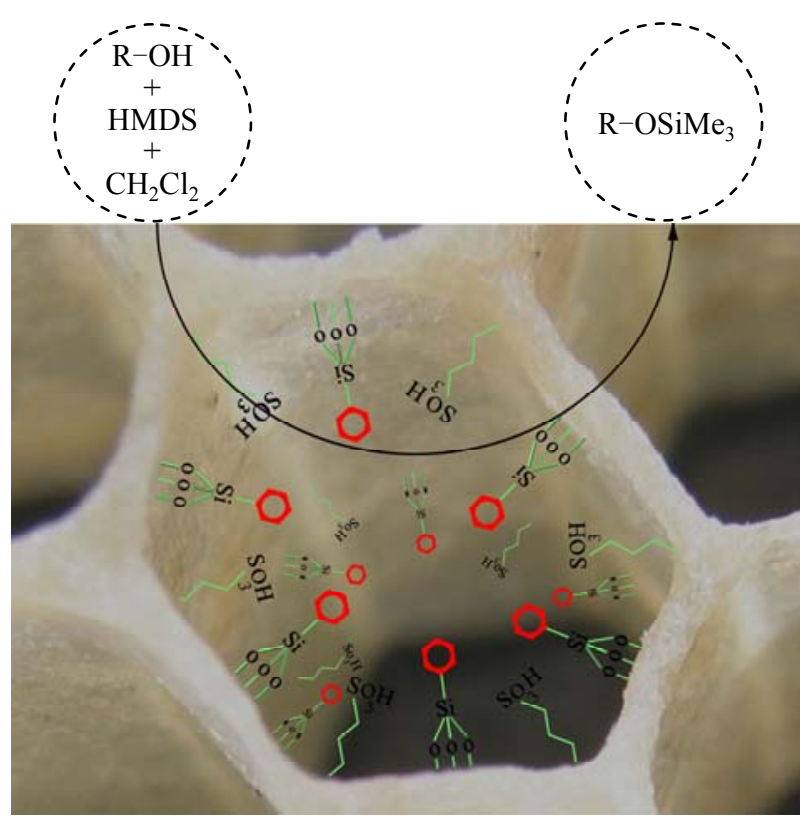

Fig. 2. Silylation reaction using catalyst 1 . 


\section{Results and discussion}

\subsection{Acid amount of SBA-15-Ph-Pr-SO ${ }_{3} \mathrm{H}$}

The amount of acid in SBA-15-Ph-Pr- $\mathrm{SO}_{3} \mathrm{H}$ was determined to be $1.61 \mathrm{mmol} / \mathrm{g}$. CHN and thermal gravimetry (TG) analysis (Fig. 3) of the catalyst confirms an acid content of $1.61 \mathrm{mmol} / \mathrm{g}$.

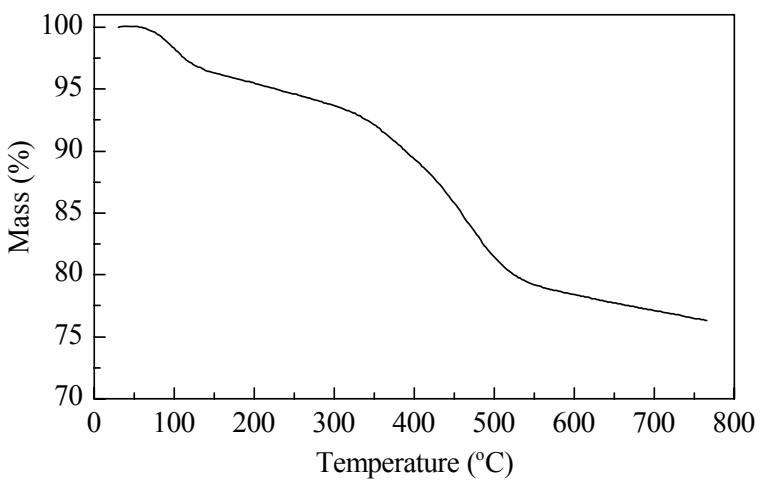

Fig. 3. TG diagram for $\mathrm{SBA}-15-\mathrm{Ph}-\mathrm{Pr}-\mathrm{SO}_{3} \mathrm{H}$.

\subsection{Trimethylsilylation of alcohols and phenols}

As a preliminary study, the catalytic evaluation of SBA-15-Ph-Pr- $\mathrm{SO}_{3} \mathrm{H}$ towards the synthesis of silyl ether from benzyl alcohol was undertaken.

In an initial attempt, a blank reaction was carried out using 1 equiv. each of benzyl alcohol and HMDS in the presence of $1 \mathrm{~mol} \%(6.3 \mathrm{mg})$ of SBA-15-Ph-Pr- $\mathrm{SO}_{3} \mathrm{H}$. These were stirred at room temperature in $\mathrm{CH}_{2} \mathrm{Cl}_{2}$ and the corresponding benzyloxytrimethyl silane was obtained in 50\% GC yield after stirring the reaction mixture for $180 \mathrm{~min}$. Increasing the reaction temperature to $35{ }^{\circ} \mathrm{C}$ improved the yield of the related product to $80 \%$ under the same reaction conditions. Subsequently, to establish the best reaction conditions the same reaction between benzyl alcohol and HMDS in $\mathrm{CH}_{2} \mathrm{Cl}_{2}$ at $35{ }^{\circ} \mathrm{C}$ was used as a model reaction to screen the effect of catalytic amounts of SBA-15-Ph$\mathrm{Pr}-\mathrm{SO}_{3} \mathrm{H}$. The results showed that no appreciable reaction occurred when benzyl alcohol and HMDS were allowed to react in dichloromethane in the absence of a catalyst and the reaction yield was only $20 \%$ of expected product after $2 \mathrm{~h}$ without a catalyst. This indicates that the catalyst is required for this reaction. Interestingly, $3 \mathrm{~mol} \%$ of catalyst 1 and 0.6 mmol of HMDS was sufficient to drive the silylation of benzyl alcohol completely over a short reaction time (100\% $\mathrm{GC}$ yield after $20 \mathrm{~min}$.). Based on these findings and to ascertain the scope and generality of this protocol we screened a range of alcohols and phenols under optimized reaction conditions. As shown in Table 1, a wide range of alcohols underwent silylation by this procedure to provide trimethyl-
Table 1 Trimethylsilylation of alcohols and phenols using SBA-15-Ph-Pr- $\mathrm{SO}_{3} \mathrm{H}$ in dichloromethane at $35^{\circ} \mathrm{C}$

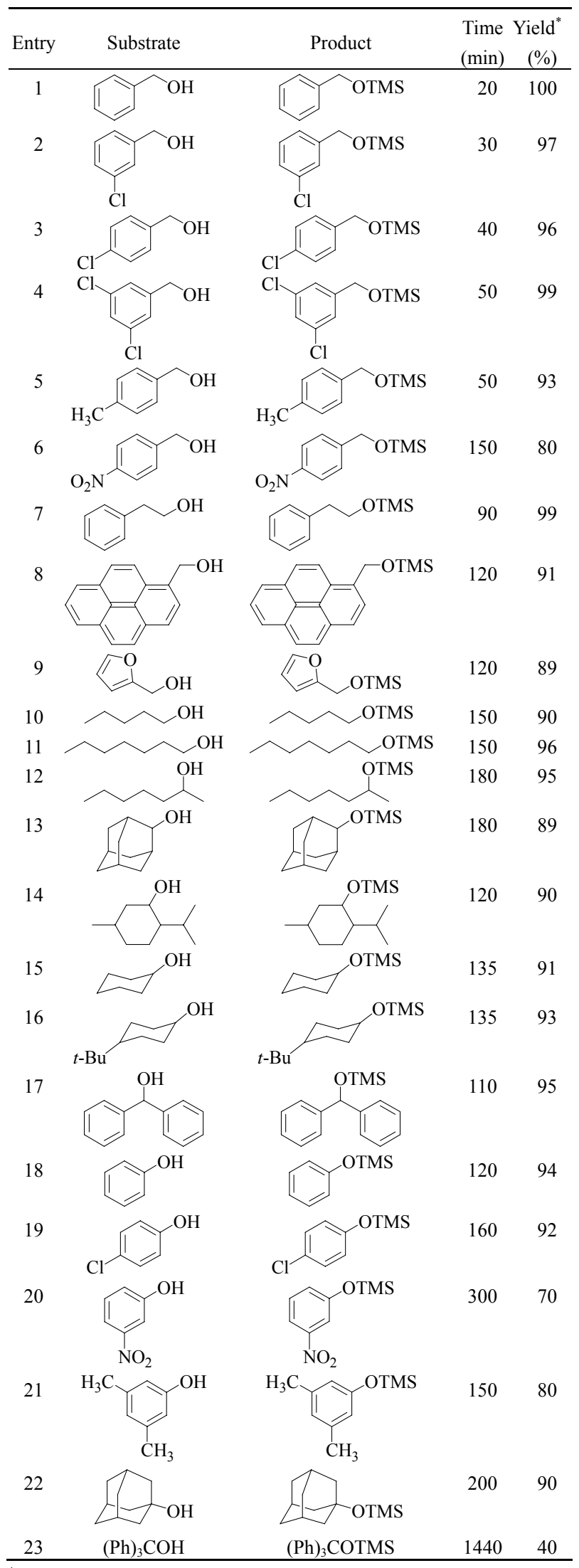

${ }^{*} \mathrm{GC}$ yield. 
silyl ether in excellent yields. Benzylic, primary, hindered and unhindered secondary, and unhindered tertiary alcohols were silylated in dichloromethane at $35^{\circ} \mathrm{C}$ and the reactions were completed over periods ranging from 20 to $1440 \mathrm{~min}$ to provide good to excellent yields of the silylated products (Table 1). In the case of primary benzylic and aliphatic alcohols the reactions were complete within $150 \mathrm{~min}$ in $\mathrm{CH}_{2} \mathrm{Cl}_{2}$ at $35{ }^{\circ} \mathrm{C}$ accompanied by a fast evolution of $\mathrm{NH}_{3}$ gas from the reaction mixture (Table 1, entries 1-11). Various benzyl alcohols with electron-donating and electron-withdrawing substituents underwent smooth silylation with excellent yields (Table 1, entries 1-6). The catalytic system is applicable to heterocyclic alcohols such as furfuryl alcohol (Table 1, entry 9). The reaction of primary aliphatic alcohols proceeded in short reaction time with excellent yields (Table 1, entries 10 and 11). From Table 1, this method is also shown to be efficient for the silylation of secondary aliphatic (Table 1, entries 12-16) and aromatic (Table 1, entry 17) alcohols. Phenol and its derivatives were also silylated in an efficient manner in excellent yields (Table 1, entries 18-21). These encouraging results prompted us to test the trimethylsilylation of hindered tertiary alcohols. Even though 1-adamantanol was converted to the corresponding silylated product in good yield (Table 1, entry 22 ), for the less reactive triphenylmethanol longer reaction time was necessary to afford the desired product. However, triphenylmethanol gave the related trimethylsilyl ether in $40 \%$ yield after $24 \mathrm{~h}$ (Table 1, entry 23). For the hindered secondary and tertiary alcohols no elimination of by-products were observed.

After achieving this favorable result, we compared the results of the silylation of alcohols with our previously reported catalyst $\left(\mathrm{MCM}-41-\mathrm{Pr}-\mathrm{SO}_{3} \mathrm{H}\right)$ to determine the effectiveness of this catalyst. Our evaluation showed that the higher conversion of starting materials for catalyst $\mathbf{1}$ in comparison to $\mathrm{MCM}-41-\mathrm{Pr}-\mathrm{SO}_{3} \mathrm{H}$ was likely due to the larger pore size of SBA-15 and the beneficial influence of phenyl groups in close proximity to the sulfonic acid groups. Based on these observations it is clear that the pore size and the hydrophobic character of catalyst $\mathbf{1}$ are crucial for the effectiveness of this sulfonic acid based catalyst for the catalysis of the silylation reaction.

Recycling of the catalyst was explored upon the silylation of benzyl alcohol with HMDS. After the completion of the first run, which affords the corresponding benzyloxytrimethyl silane in $100 \%$ yield, the products and the solvent were removed from the reaction mixture using a syringe, and fresh reactants and solvent were added to the catalyst to run the second silylation reaction. Gratifyingly, SBA-15-Ph$\mathrm{Pr}-\mathrm{SO}_{3} \mathrm{H}$ was successfully reused in eighteen successive runs and exhibited consistent activity to afford an average yield of $99.5 \%$ with virtually no significant loss of performance, which clearly demonstrates the practical recyclability of this catalyst. This reusability demonstrates the high stability and turnover of the catalyst under the conditions employed.

To compare the catalytic potential of catalyst 1 with some recently reported catalysts, we studied the silylation of benzyl alcohol using HMDS in the presence of various catalysts (Table 2). The results show that some protocols took longer, some used dangerous materials with reduced isolated yields and some used non-recoverable catalysts, which clearly shows that $\mathrm{SBA}-15-\mathrm{Ph}-\mathrm{PrSO}_{3} \mathrm{H}$ should be considered one of the best choices.

\section{Conclusions}

SBA-15-Ph-Pr- $\mathrm{SO}_{3} \mathrm{H}$ was a highly efficient and recoverable catalyst for the silylation of alcohols and phenols by HMDS in dichloromethane at $35^{\circ} \mathrm{C}$. The most striking features of this method are excellent catalytic capacity, outstanding stability, exceedingly simple workup, and multiple reuse of $\mathrm{SBA}-15-\mathrm{Ph}-\mathrm{Pr}-\mathrm{SO}_{3} \mathrm{H}$. As a consequence, this system represents a substantial improvement over previous methods wherein product separation produces a large amount of waste. In addition, by this method, primary, bulky secondary, tertiary, and phenolic hydroxyl functional groups are protected with excellent yields. Further studies will focus on the exploration of this solid sulfonic acid for other types of functional group transformations.

Table 2 Comparison of the catalytic efficiency of SBA-15-Ph-Pr-SO $\mathrm{S}_{3} \mathrm{H}$ with other reported catalysts for the trimethylsilylation of benzyl alcohol using HMDS

\begin{tabular}{|c|c|c|c|c|c|c|}
\hline Entry & Catalyst (amount) & Solvent & Temperature $\left({ }^{\circ} \mathrm{C}\right)$ & Time (min) & Yield (\%) & Ref. \\
\hline 1 & SBA-15-Ph-Pr-SO ${ }_{3} \mathrm{H}(3 \mathrm{~mol} \%)$ & $\mathrm{CH}_{2} \mathrm{Cl}_{2}$ & 35 & 20 & 100 & this work \\
\hline 2 & $\mathrm{H}_{3} \mathrm{PW}_{12} \mathrm{O}_{40}(1 \mathrm{~mol} \%)$ & solvent free & $55-60$ & 23 & 100 & {$[18]^{\mathrm{a}}$} \\
\hline 3 & $\mathrm{LiClO}_{4}(50 \mathrm{~mol} \%)$ & solvent free & $\mathrm{rt}$ & 25 & 99 & {$[19]^{\mathrm{a}}$} \\
\hline 4 & $\mathrm{LaCl}_{3}(10 \mathrm{~mol} \%)$ & $\mathrm{CH}_{2} \mathrm{Cl}_{2}$ & $\mathrm{rt}$ & 180 & 91 & {$[23]^{\mathrm{a}, \mathrm{b}}$} \\
\hline 5 & HY Zeolite $(0.1 \mathrm{~g})$ & solvent free & $55-60$ & 120 & 80 & {$[18]^{\mathrm{a} b \mathrm{~b}}$} \\
\hline 6 & $\mathrm{Bi}(\mathrm{OTf})_{3}(5 \mathrm{~mol} \%)$ & solvent free & $\mathrm{rt}$ & 4 & 99 & {$[25]^{\mathrm{a}, \mathrm{b}, \mathrm{c}}$} \\
\hline 7 & DABCO-Br $(0.1 \mathrm{~mol} \%)$ & $\mathrm{CH}_{3} \mathrm{CN}$ & $\mathrm{rt}$ & 10 & 100 & {$[28]^{\mathrm{a}, \mathrm{d}}$} \\
\hline
\end{tabular}

${ }^{a}$ No recovery. ${ }^{b}$ Long reaction time. ${ }^{\mathrm{c}} 1 \mathrm{mmol}$ HMDS was used. ${ }^{\mathrm{d}} 0.8 \mathrm{mmol}$ HMDS was used. 


\section{Acknowledgments}

The authors acknowledge the Islamic Azad University of Qaemshahr Research Councils for supporting this work.

\section{References}

1 Greene T W, Wuts P G M. Protective Groups in Organic Synthesis. 2nd Ed. New York: Wiley, 1991

2 Kocienski P J. In: Enders R, Noyori R, Trost B M eds. Protective Groups. Thieme: Stuttgart, 1994

3 Langer S H, Connell S, Wender I. J Org Chem, 1958, 23: 50

4 Morita T, Okamoto Y, Sakurai H. Tetrahedron Lett, 1980, 21: 835

5 Veysoglu T, Mitscher L A. Tetrahedron Lett, 1981, 22: 1299

6 Hatano B, Toyota S, Toda F. Green Chem, 2001, 3: 140

7 Bifiss A, Zecca M, Basato M. Green Chem, 2003, 5: 170

8 Watahiki T, Matsuzaki M, Oriyama T. Green Chem, 2003, 5: 82

9 Bideau F L, Henique J, Samuel E, Coradin T. Chem Commun, 2001: 1408

10 Huang X, Craita C, Awad L, Vogel P. Chem Commun, 2005: 1297

11 Ito H, Takagi K, Miyahara T, Sawamura M. Org Lett, 2005, 7: 3001

12 Iida A, Horii A, Misaki T, Tanabe Y. Synthesis, 2005: 2677

13 Shirini F, Zolfigol M A, Paktinat M. Synthesis, 2006: 4252

14 Bruynes C A, Jurriens T K. J Org Chem, 1982, 47: 3966

15 Gauttret P, El-Ghamarti S, Legrand A, Coutrier D, Rigo B. Synth Commun, 1996, 26: 707

16 Goldschmidt A G T. DE 2758 884. 1978

17 Zhang Z H, Li T S, Yang F, Fu C G. Synth Commun, 1998, 28 :
3105

18 Mojtahedi M M, Saidi M R, Bolourchian M, Heravi M M. Phosphorus Sulfur Silicon Relat Elem, 2002, 177: 289

19 Karimi B, Golshani B. J Org Chem, 2000, 65: 7228

20 Firouzabadi H, Iranpoor N, Amani K, Nowrouzi F. J Chem Soc, Perkin Trans I, 2002: 2601

21 Azizi N, Saidi M R. Organometallics, 2004, 23: 1457

22 Ghorbani-Vaghei R, Zolfigol M A, Chegeny M, Veisi $\mathrm{H}$. Tetrahedron Lett, 2006, 47: 4505

23 Shuirakawa E, Hironaka K, Otsuka H, Hayashi T. Chem Commun, 2006: 3927

24 Reis P M, Royo B. Catal Commun, 2007, 8: 1057

25 Narsaiah A V. J Organomet Chem, 2007, 692: 3614

26 Ghorbani-Choghamarani A, Zolfigol M A, Hajjami M, Jafari S. J Chin Chem Soc, 2008, 55: 1208

27 Kadam S T, Kim S S. J Organomet Chem, 2009, 694: 2562

28 Niknam K, Zolfigol M A, Chehardoli G, Dehghanian M. Chin J Catal, 2008, 29: 901

29 Olah G A, Iyer P S, Prakash G K S. Synthesis, 1986: 513

30 Corma A. Chem Rev, 1995, 95: 559

31 Herron N, Farneth W E. Adv Mater, 1996, 8: 959

32 Horton B. Nature, 1999, 400: 797

33 Anastas P T, Kirchhooff M M. Acc Chem Res, 2002, 35: 686

34 Okuhara T. Chem Rev, 2002, 102: 3641

35 Zareyee D, Karimi B. Tetrahedron Lett, 2007, 48: 1277

36 Karimi B, Zareyee D. Org Lett, 2008, 10: 3989

37 Karimi B, Zareyee D. J Mater Chem, 2009, 19: 8665

38 Karimi B, Zareyee D. Tetrahedron Lett, 2005, 46: 4661

39 Zareyee D, Ghandali M S, Khalilzadeh M A. Catal Lett, 2011, 141: 1521

40 Margolese D, Melero J A, Christiansen S C, Chmelka B F, Stucky G D. Chem Mater, 2000, 12: 2448 